\title{
Correction to: Efficacy of initial temozolomide for high-risk low grade gliomas in a phase II AINO (Italian Association for Neuro-Oncology) study: a post-hoc analysis within molecular subgroups of WHO 2016
}

\author{
Roberta Rudà 10 - Alessia Pellerino ${ }^{1} \cdot$ Andrea Pace $^{2} \cdot$ Carmine Maria Carapella $^{2} \cdot$ Cristina Dealis $^{3} \cdot$ Manuela Caroli $^{4}$. \\ Marina Faedi ${ }^{5}$. Lorenzo Bello ${ }^{6}$. Enrica Migliore ${ }^{7}$. Giulia Marchese ${ }^{1} \cdot$ Luca Bertero $^{8} \cdot$ Paola Cassoni $^{8}$. \\ Riccardo Soffietti ${ }^{1}$
}

Published online: 5 November 2019

(c) Springer Science+Business Media, LLC, part of Springer Nature 2019

\begin{abstract}
Correction to: Journal of Neuro-Oncology (2019) 145:115-123 https://doi.org/10.1007/s11060-019-03277-x
\end{abstract}

The third and fourth authors' affiliation was incorrectly specified in the original publication. It is correctly shown here.

Publisher's Note Springer Nature remains neutral with regard to jurisdictional claims in published maps and institutional affiliations.

The original article can be found online at https://doi.org/10.1007/ s11060-019-03277-x.

Roberta Rudà

rudarob@hotmail.com

1 Department of Neuro-Oncology, University and City of Health and Science Hospital, Via Cherasco 15, 10126 Turin, Italy

2 Department of Neurosurgery, I.R.C.C.S. Regina Elena National Cancer Institute, Rome, Italy

3 Department of Medical Oncology, Regional Hospital, Bolzano, Italy

4 Department of Neurosurgery, Regional Hospital, Milan, Italy

5 Department of Medical Oncology, Regional Hospital, Cesena, Italy

6 Department of Neurosurgery, University of Milan, Milan, Italy

7 Unit of Cancer Epidemiology (CPO Piemonte), University of Turin, Turin, Italy

8 Department of Biomedical Sciences, University and City of Health and Science Hospital, Turin, Italy 